CHAPTER 8

\title{
Psychological Treatments for Dermatological Conditions
}

\author{
Andrea W.M. Evers", Saskia Spillekom-van Koulil and Sylvia van Beugen \\ Leiden University, Institute of Psychology, Health, Medical and Neuropsychology Unit, Faculty of \\ Social and Behavioral Science, Leiden, and Radboud University Medical Centre, Department of \\ Medical Psychology, Nijmegen, The Netherlands
}

\begin{abstract}
The impact of dermatological conditions on a patient's life is frequently underestimated. Patients with skin conditions experience several physical complaints, including itch, pain and fatigue. Furthermore, in comparison to the general population, patients report a decreased psychological well-being, lowered quality of life and feelings of stigmatization and shame. Psychological treatments are widely used in addition to regular dermatological treatments to improve physical and psychological functioning of patients with chronic skin conditions. These treatments are usually aimed at changing the psychosocial factors that can influence the onset and/or course of skin conditions, such as dysfunctional coping behaviors, itch-scratching problems and stress. There are unimodal interventions in which single treatments are used, for example psychoeducation or relaxation exercises, and multimodal treatments in which a variety of different interventions are applied based on cognitive-behavioral therapy and self-management principles. Furthermore, a distinction can be made between interventions that focus primarily on skin-related psychosocial problems, interventions that focus on itch-scratching problems, and interventions that are focused on psychiatric problems in the dermatological practice. This chapter gives an overview on the psychosocial factors relevant for dermatological conditions, relevant diagnostic methods and the content and scientific evidence of specific psychological treatments in these different categories.
\end{abstract}

\footnotetext{
* Corresponding author Andrea W.M. Evers: University of Leiden, Institute of Psychology, Health, Medical and Neuropsychology Unit, Faculty of Social Science, PO Box 9555 / 2300 RB Leiden / The Netherlands; Tel: +31-71-527 6891; Fax: +31-71-527 3619; E-mail: a.evers@fsw.leidenuniv.nl.
}

Klas Nordlind \& Anna Zalewska-Janowska (Eds.) All rights reserved-@ 2016 Bentham Science Publishers 
Keywords: Cognitive-behavioral therapy, Dermatological conditions, Habit reversal, Itch-scratching problems, Psychological treatment, Stress management.

\section{INTRODUCTION}

The impact of skin conditions on a patient's everyday life is frequently underestimated. Although the influence of psychological factors on the skin has been recognized since a long time, systematic research on psychological factors and treatments has only begun in the last decades. Research shows that people with skin conditions experience more physical symptoms, such as itch, pain and fatigue than the general population [1]. Patients additionally report more anxiety, tension and depressive feelings, and experience social restrictions [2 - 4]. Psychological treatments have consequently been regularly proposed as possible added benefit for the regular dermatological treatments. Based on the existing research evidence focusing particularly on highly prevalent chronic skin conditions, this chapter focuses on the psychosocial factors relevant for dermatological conditions and their impact on daily life, relevant diagnostic methods and psychological treatments.

\section{PREVALENT PROBLEMS IN PATIENTS WITH DERMATOLOGICAL CONDITIONS}

Skin conditions are generally characterized by their fluctuating course and they are often accompanied with physical complaints such as itch, desquamation or pain. Research shows that chronic skin conditions, such as psoriasis and eczema, are accompanied by physical, emotional and social problems and can lead to multiple restrictions in everyday life [5]. Patients report decreased psychological well-being and lower quality of life compared to the general population $[3,6,7]$. For 20 to 40 percent of this group, symptoms are so severe that they are considered a risk group for long-term adjustment problems which require further treatment [4]. The decreased psychosocial well-being can in turn negatively affect the skin condition; for example, patients with psoriasis who also have a high level of psychological distress benefit less from treatments such as phototherapy [8].

Patients with chronic skin conditions often state that 'itch is worse than pain'. Accordingly, itch is the most prominent complaint in most skin conditions. More 
than half of the patients with chronic skin conditions report to be experiencing symptoms of itch [1,9]. The definition of itch, 'an unpleasant sensation provoking the desire to scratch', implies the strong correlation between itch and scratching. Frequent scratching can however lead to skin damage which can in turn aggravate skin conditions [9]. In many patients, scratching leads to relief in the short-term, while feelings of helplessness, shame and guilt play a big role in the long-term. Reactions from the environment towards the scratching behavior ('Could you please stop scratching yourself') can increase these feelings and cause irritation and tensions. Many patients especially suffer from itch at night, leading to sleep problems, chronic fatigue, concentration problems and increased irritability during the day. Over time this can lead to increased avoidance of everyday activities and in the longer term to depressive moods [3]. Accordingly, patients with chronic itch report lower psychological and social well-being than the general population [2 - 4]. Besides itch, skin conditions can also be accompanied by pain [1], for example in patients with chronic ulcera. In addition, eczemas or open wounds caused by scratching can also cause painful fissures in the skin.

Patients with chronic skin conditions additionally report more restrictions in social activities, work and leisure than the general population. Multiple factors can play a role in this. Medical treatments of skin conditions are often quite time intensive, for example when an ointment has to be applied to the whole body several times a day. Additionally patients report feeling restricted by the effect of ointments on their clothes and by the smell of certain ointments such as coal tar ointments. Due to the visibility of skin conditions, many patients experience social stigmatization, shame and social anxiety [3, 10, 11]. A study by Ginsburg and Link [12] revealed that about 20 percent of patients with psoriasis experienced being sent away from sports, hairdressers or swimming facilities because of their skin condition. However, the proportion of patients that suffer from 'the experience of stigmatization' is far greater. Indeed, Lu et al. [13] found that about 80 percent of patients with psoriasis and atopic eczema felt stigmatized by others because of their skin disease at least once, 30 percent of which severely. The experience of stigmatization is one of the strongest determinants of perceived restrictions in everyday life $[14,15]$ and can lead to decreased self-confidence and feelings of shame. These feelings can cause people to isolate themselves and avoid being in 
public (for example, at restaurants, sports centers or beaches). Additionally, such feelings can lead to fear of interacting with others, which in turn can affect interpersonal relationships [16].

Certain skin conditions that develop at early age, for example atopic eczema, or develop at a certain developmental phase, such as acne, can affect psychosocial development. Children and adolescents who suffer from skin conditions report a lower quality of life compared to peers with other conditions that occur during childhood, such as asthma and diabetes [17]. Apart from complaints of itch and pain this group can also experience emotional and social problems, such as shame, sleep problems, restrictions in hobbies and restrictions in entering into relationships $[17,18]$. Additionally, chronic skin conditions do not only affect the child but the whole family, so that parents are found to have lower quality of life and higher rates of psychological distress [19].

A relatively rare category of skin conditions are those in which the complaints are considered mainly psychogenic. Conditions which are characterized by self-harm fall into this category, for example factitious disorder, where patients hurt themselves systematically and repeatedly in order to be diagnosed with a skin condition (this condition is also known as Münchausen's syndrome or dermatitis artefacta) [20, 21]. Furthermore there are several compulsive disorders that express themselves on the skin, such as trichotillomania (the compulsion to pull out one's hair and eyebrows) and skin picking disorder or dermatillomania (the compulsion to continually pick or rub one's skin). Conditions such as delusional infestation, in which patients strongly believe that they are infested by parasites, also fall into this category. Patients suffering from this condition often experience itch and/or pain as well as wounded skin caused by scratching. Despite the psychiatric nature of these conditions, patients suffering from them often visit the dermatologist because of their skin complaints. In recent years more and more attention has been paid to body dysmorphic disorder, in which patients are preoccupied with a supposedly objective deficiency in their appearance, which is often related to their skin. Obsessive preoccupation with one's skin, for example frequently looking at it in the mirror, can also be experienced by patients with for example acne vulgaris or alopecia (excessive hair loss). 


\section{PSYCHOSOCIAL FACTORS IN DERMATOLOGICAL CONDITIONS}

On average patients with skin conditions have a lower quality of life than the general population. However, there are large differences between individual patients. As in other somatic conditions these differences cannot be explained by the severity of the skin condition alone. Psychosocial factors can influence the onset and/ or the course of certain skin conditions.

About two-thirds of patients with psoriasis and atopic eczema report that stress influences the course of their condition $[3,22,23]$. This influence of stress on the skin is a possible starting point for psychological interventions. For example, improving stress coping mechanisms by means of stress management trainings could affect the severity of a skin condition. The relationship between stress and the course of a condition could in part be explained by the role that the immune system plays in chronic inflammatory skin diseases. More specifically, neuroendocrine and immune mechanisms (for example cortisol and cytokines) can be influenced by stress and can in turn influence chronic skin-related inflammatory activity $[22,24]$. Indeed, several prospective studies found a link between stressors and the course of conditions [23 - 25]. Accordingly, in patients with atopic eczema, subjective stress proved to predict disease severity on the following day [26]. Additionally, in patients with psoriasis, high levels of daily stressors were associated with an increase in disease severity and itch four weeks later [24, 25]. Stressors can influence wound healing [27], although this relationship has not been studied in patients with skin conditions. Some correlations have also been found between for example stressors, cortisol and indicators of disease severity $[7,22,24]$, however future research is necessary to further investigate these relationships. Stress influences skin conditions, and skin conditions cause stress for the patient resulting in a vicious cycle. Itch is correlated with an increased activity of the autonomic and central nervous system which expresses itself as increased anxiety. Also the visibility of the condition and the perceived stigmatization is a significant stressor for patients. Additionally, many patients report that time-intensive treatments and their impact on everyday life can lead to stressful situations.

An important mediating factor between stressors and disease outcomes is the way 
patients cope with their condition, including their opinions and attitudes about it, and the perceived support from their environment. Many patients with skin conditions experience feelings of helplessness when trying to cope with their condition. In particular the unpredictable course of a skin condition and the lack of control can make coping more difficult. In line with research on other chronic physical conditions there is some indication that a more passive, avoiding coping style and catastrophizing cognitions can negatively affect the course of a condition and the success of a treatment [7, 8, 25, 28]. Furthermore, studies in people with atopic eczema and psoriasis have revealed connections between perceived helplessness in coping with the condition and decreased physical and psychological well-being [2]. In many physical conditions, perceived social support is an important predictor of long-term functioning. Considering the visibility of skin conditions and their impact on daily life these findings could be especially relevant for skin conditions. However, research on this relationship has so far received relatively little attention [2]. Health behavior can also affect the course of skin conditions. Given that daily skin care with ointments requires a lot of self-reliance, time and effort, following treatment prescriptions is often difficult for dermatological patients. Research shows that approximately $44 \%$ of patients do not follow their treatment prescriptions exactly [29, 30]. Besides lack of adherence, lifestyle factors can also affect the course of a chronic physical condition. There are, for example, indications that in patients with chronic ulcer (open wound), healing of venous ulcers can be slowed by lack of exercise and obesity [31].

Increasing attention is paid to scratching behavior as a perpetuating factor of itch in chronic skin conditions [3,9]. Primarily, scratching is an automatic action to reduce itch. Frequent scratching, however, leads to skin damage and the healing process of these scratching wounds is again accompanied by itch, which may lead to a vicious cycle of itch-scratching problems. Additionally, research in learning theory shows that scratching can lead to a generalized conditioned response to stressors and other environmental stimuli in the long term [9]. In these cases, people scratch not only in response to itch but also as a reaction to stress, anxiety, boredom or other stimuli that have been associated with scratching over time. This scratching behavior can be aggravated by reinforcing factors from the 
environment. For example, the attention that a child receives from his/her parents can contribute to maintaining the problematic scratching behavior. Through the effects of skin damage due to scratching behavior, this itch-scratch problem can have a significant and persisting influence on the severity of the disease and the effects of dermatological treatments $[9,32]$.

\section{PSYCHOLOGICAL ASSESSMENT AND DIAGNOSTICS IN DERMATOLOGICAL CONDITIONS}

Referral to a psychologist or other psychosocial counselor is common when dermatological interventions have insufficient results, or when there is a possibility of psychosocial problems. In standardized interviews, it is important to identify and assess psychosocial symptoms as well as those factors that can influence the skin condition, such as stressors, health behavior, adherence, social anxiety, itch-scratching problems, or overall coping. Standardized questionnaires can be used in support of the information obtained from the interview in order to determine the right treatment. Several questionnaires with adequate psychometric qualities are available to identify the overall physical, psychological and social well-being of patients with skin conditions. The most widely used questionnaire is the Dermatological Life Quality Index (DLQI) [33], a one-dimensional, dermatology-specific quality of life questionnaire consisting of ten items for which extensive normative data has been published for a wide variety of skin conditions [33]. The more extensive Skindex [34] is a questionnaire which assesses the physical, emotional and social functioning of a patient with the help of several scales, and which is validated for various chronic skin conditions. Additionally, questionnaires for other physical conditions have been adapted to assess chronic skin conditions. For example, the Impact of Chronic Skin Disease on Daily Life (ISDL) [35] which makes it possible to compare how different physical conditions impact psychological and social well-being. A widely used instrument to assess the quality of life in children with skin conditions is the Children's Dermatology Life Quality Index (CDLQI) [36]. In addition to these questionnaires about skin conditions, generic instruments are frequently used such as the Short Form Health Status Survey (SF-36) [37] which can be used to assess the physical and psychological quality of life in people with chronic conditions. A disadvantage of generic questionnaires is that they do not measure specific 
physical effects of skin conditions, such as itch, and do not make use of available instruments which identify skin-related cognitive and behavioral factors.

Furthermore, instruments are available that measure skin-related cognitive and behavioral factors. The above mentioned ISDL, for example, also measures behavioral factors such as itch-scratching problems, illness cognitions of perceived helplessness and acceptance and the amount of social support. Other similar questionnaires are the Itching Cognitions Questionnaire (ICQ) [38 - 40] which assesses a variety of cognitions about itch such as catastrophizing and the Adjustment to Chronic Skin Diseases Questionnaire (ACS) [41] which measure different skin-related illness cognitions and coping strategies for coping with skin conditions. Additionally, specific questionnaires have been developed to measure the degree of stigmatization [35, 42, 43]. Similar instruments have also been developed for children and adolescents with atopic eczema [44]. Finally, stressors and personality traits are usually measured with generic questionnaires that have been validated for various chronic somatic and mental conditions.

\section{PSYCHOLOGICAL TREATMENTS FOR PATIENTS WITH DERMATOLOGICAL CONDITIONS}

Psychological treatments are widely used to improve the psychosocial and physical well-being of people with chronic skin conditions [3, 22]. These interventions vary in the degree to which they attempt to change behaviors. There are unimodal interventions in which single treatments are used, for example psycho-education or relaxation exercises, and multimodal treatments in which a variety of different interventions are applied based on cognitive-behavioral therapy and self-management principles. These interventions usually focus on how patients cope with disease-related factors such as itch, scratching or experienced stigmatization. In this, a distinction can be made between interventions that focus primarily on skin-related psychosocial problems, interventions that focus on itch-scratching problems, and interventions that are focused on psychiatric problems in the dermatological practice. The content of, and scientific evidence for these specific psychological treatments in the different categories will be described below. 


\section{Treatments of Skin-Related Psychosocial Problems}

Important skin-related factors in chronic skin conditions that can be targeted by psychological treatments are social anxiety, depression, perceived stigmatization and dysfunctional coping strategies, such as avoidance behavior, acceptance and adjustment problems. In these cases, cognitive-behavioral methods are used that have been proven effective for these kinds of problems [3, 22, 45, 46].

Unimodal treatments that consist of psycho-education have so far been used to target psychosocial problems in children and adolescents with skin-conditions and their parents. A review of randomized controlled trials in patients with chronic skin conditions reveals that in particular interventions involving a multidisciplinary team and several meetings, participants reported an improved quality of life and reduced disease severity [47]. One example is the intervention of Staab et al. [48] in which a distinction was made between different age groups, and children with atopic eczema and their parents were provided with a structured psychoeducation, consisting of six sessions which were led by a multidisciplinary team (among others a dermatologist, a psychologist, a nurse and a dietician). Following this intervention, patients reported reduced disease severity. Similar results were found with educational interventions in adults [47].

Because of the connection between stress-related factors and skin conditions, relaxation exercises and stress-management interventions are frequently used in the treatment of skin conditions. Among the feasible exercises are various relaxation techniques such as progressive relaxation, autogenic training, visualization exercises, biofeedback, but also multimodal interventions which integrate, among others, cognitive restructuring techniques and methods which strengthen problem-solving skills. The rationale behind such interventions is that by changing the stress response one can also influence inflammatory activity and diseases severity. A recent study found that patients with atopic eczema that participated in a short-term stress management training indeed showed a decreased cortisol response during exposure to a psychosocial stressor compared to the control group [49]. However, in this study no effect on the severity of the eczema was found, possibly because the sample was too small or the follow-up too short. There are also indications that patients with psoriasis and atopic eczema 
benefit from stress-focused relaxation therapy [50], which resulted in decreased disease severity in patients with atopic eczema [51] and a reduction of required phototherapy sessions in patients with psoriasis [52].

Especially in patients with psoriasis and atopic eczema, multimodal cognitivebehavioral treatments have been shown to be effective, for example in improving emotional functioning, reducing disease severity and itching, and increasing the effectiveness of regular dermatological treatments. An example of these treatments is short-term cognitive-behavioral group therapy in patients with psoriasis. In addition to information about the diseases, this short-term group therapy uses stress management, relaxation therapy and cognitive therapy which focuses on disease-related attitudes, social anxiety and perceived stigmatization. In one study patients reported reduced disease severity, less disease-related stress, anxiety and depression compared to the control group directly after the treatment and at a follow-up assessment six month later [53]. Also, a treatment consisting of twelve sessions focusing on education, relaxation, techniques to control scratching, which made use of self-control techniques and habit reversal, stressmanagement and improvement of communication, was effective in improving the severity of the skin condition [51].

A new development is the application of psychological interventions in the form of education, self-management and cognitive behavioral therapy via the Internet (eHealth), which is increasingly used in cognitive-behavioral treatments of patients with chronic somatic conditions, including skin diseases [54, 55]. eHealth has several important advantages, such as a greater reach of care and better access to care, less time consumption and travel costs for the patient and a great flexibility for therapist and patient. There are indications that eHealth interventions can be as effective as face to face treatments for various physical ailments [56]. Additionally, psychological interventions focused on mindfulness and acceptance, which are increasingly used in treating chronic conditions, offer promising possibilities for the psychological treatment of skin conditions [52].

Furthermore, multimodal interventions for children have been developed that make use of education in combination with cognitive behavioral therapy and relaxation therapy [57]. For example, an intervention focused on education, stress 
management and improvement of social skills in children and adolescents with psoriasis proved effective in improving skin complaints, self-image and social constraints [58]. An example is the Supportive Program for Education, Coping and Training of Parents and Children with Psoriasis and Eczema (SPECTRUM), a multidisciplinary group treatment for children with psoriasis and eczema and their parents. During four meetings led by a dermatologist, a clinical psychologist, and a nurse, it is attempted to increase the self-reliance of children and their parents in dealing with the condition [59].

\section{Treatments of Itch-Scratching Problems}

A considerable amount of research has been conducted on the effects of cognitive behavioral treatments specifically focused on itch-scratching problems. In clinical practice, these treatments are frequently applied in combination with psychological treatments for skin-related problems. The primary goal of treatments for itch-scratching problems is to improve the way patients cope with itch and to decrease scratching behavior. In the long-term, it is also expected that itch and the severity of the skin disease is reduced and patients' quality of life improved. The treatments thus have the following two areas of focus: dealing with itch, and dealing with scratching. In dealing with itch, attention has to be paid to the regular application of skin care routines (for example, application of ointments), avoidance of itch-triggering stimuli or situations (for example transpiration, in many skin conditions) and the application of itch- and stressdecreasing measures (for example, relaxation exercises). In dealing with scratching, raising awareness of scratching habits (for example, through registration of scratching behavior) takes a central role and patients are taught different methods to control scratching. The best known method for controlling scratching is 'habit reversal' in which patients learn to replace scratching with an alternative behavior [60]. A basic principle of these treatments is to increase the responsibility and autonomy of the patient in dealing with itch and scratching. For example, through education and registration exercises, patients become aware of early signals of skin deterioration (for example, more itch, scales on the skin, red skin). Subsequently, they try to recognize these signals at an early stage in their daily lives in order to take appropriate action (for example, applying more ointments, protecting the skin by using bandages, adding more relaxation to daily 
lives), with which further aggravation can be prevented. In case of very severe itch, this intervention can also be combined with pharmacological therapies, such as antihistamines or antidepressants in a very low dosage [61].

Research mainly focuses on multimodal interventions that proved to be effective in reducing disease activity and/ or reducing the degree of itch and scratching in patients with atopic eczema or other chronic skin conditions in adults, children and adolescents [32, 40, 48, 51]. The active mechanisms of these interventions have so far received little attention. It is however known, that in patients with atopic eczema scratch-management methods including habit reversal are effective [62]. Regarding the duration of the treatment, there are indications that in addition to the proven effective treatments that include twelve meetings [51], research suggests that a short-term multidisciplinary group treatment of five meetings can have clinically significant effects in the long-term [32]. The training was provided by a cognitive behavioral therapist and a specialized nurse, using the aforementioned combination of methods aimed at reducing itch-scratching problems [32].

\section{Treatments of Psychiatric Problems in Dermatological Practice}

In patients with psychiatric problems and severe psychopathology, such as selfinflicted skin lesions in factitious disorder (dermatitis artefacta), delusional infestation, trichotillomania, skin picking disorder and body dysmorphic disorder, the nature of the condition implies that psychological treatments tend to be more complex and lengthy. In addition to that, the referral to the psychologist or psychiatrist can be a significant challenge, especially in patients with factitious disorder, delusional infestation or body dysmorphic disorder, who can often experience this as a sign of lack of understanding. In these cases, a multidisciplinary psychodermatological approach of the dermatologist and the psychologist/psychiatrist is critical.

For some conditions, it is known that patients benefit from cognitive-behavioral therapy. For example in patients with trichotillomania, behavioral therapies for impulse control, such as habit reversal, have been applied with promising results [63]. Also for skin picking (dermatillomania) effective treatments have been 
developed, which use among other things habit reversal and cognitive restructuring techniques $[64,65]$. For body dysmorphic disorder, effective behavioral therapies have been developed, which focus on exposure to (fear triggering) social stimuli, response prevention (for example looking at oneself in the mirror, omitting superfluous make-up) and changing irrational beliefs and cognitions about one's own appearance $[66,67]$.

In conditions that have not been researched systematically yet, such as selfinflicted lesions in factitious disorder, cognitive-behavioral approaches are advised in the medical context, aimed at reducing or eliminating self-injurious behavior. In these cases, initial attention has to be paid to building trust between the patient and the dermatologist. The consulting psychologist or psychiatrist is present in the background to carefully assess at which stage of the therapy confrontation is appropriate. It is important that a neutral attitude is adopted towards the self-injurious behavior. In most cases, a psychotherapeutic treatment is focused on, among other things, elucidating the possible functions of this behavior. Learning new coping strategies is necessary to eliminate self-injurious behavior [20]. Especially in delusions such as delusional infestation, these treatments tend to be combined with pharmacotherapy [3, 22].

\section{CONCLUSION}

Considering the high prevalence of physical, emotional and social problems in patients with skin conditions, it is crucial that these problems are recognized at an early stage, in order to provide additional psychological care if necessary. However, in the clinical practice of dermatological consultation, limited attention is paid to potential psychosocial consequences of skin conditions and availability of multidisciplinary approaches focusing on systematic screening and corresponding treatments are only incidental $[16,68]$. It is therefore of great importance that increased attention is paid to psychological research and clinical applications in the field of dermatology, such as the implementation of screening instruments in dermatological practice. Also, further development, evaluation and implementation of psychological interventions for skin-related problems, itchscratching problems and psychiatric problems in dermatological practice is important, as the existing evidence shows promising results for physical and 
psychological functioning in skin patients [46]. Applications through the Internet also offer promising starting points to further facilitate the psychodermatological approach [54 - 56]. In addition, more research is needed to further elucidate the possible interactions between psychological and skin-related (inflammatory-) mechanisms, which will provide possible starting points to further specify psychological and psychopharmocological interventions.

\section{CONFLICT OF INTEREST}

An adjusted version of this chapter has previously been published in Dutch as "Spillekom-van Koulil, S. \& Evers, A.W.M. (2013). Psychologische behandeling van huidaandoeningen [Psychological treatments of skin diseases]. Directieve therapie, 33, 4, 336-361".

\section{ACKNOWLEDGEMENTS}

Declared none.

\section{REFERENCES}

[1] Verhoeven EW, Kraaimaat FW, van de Kerkhof PC, et al. Prevalence of physical symptoms of itch, pain and fatigue in patients with skin diseases in general practice. Br J Dermatol 2007; 156(6): 1346-9. [http://dx.doi.org/10.1111/j.1365-2133.2007.07916.x] [PMID: 17535233]

[2] Evers AW, Lu Y, Duller P, van der Valk PG, Kraaimaat FW, van de Kerkhof PC. Common burden of chronic skin diseases? Contributors to psychological distress in adults with psoriasis and atopic dermatitis. Br J Dermatol 2005; 152(6): 1275-81.

[http://dx.doi.org/10.1111/j.1365-2133.2005.06565.x] [PMID: 15948993]

[3] Stangier U, Ehlers A. Stress and anxiety in dermatological disorders. In: Mostofsky DI, Barlow DH, Eds. The management of stress and anxiety in medical disorders. Needham Heights: Allyn \& Bacon 2000; pp. 304-43.

[4] Verhoeven EW, Kraaimaat FW, van de Kerkhof PC, et al. Psychosocial well-being of patients with skin diseases in general practice. J Eur Acad Dermatol Venereol 2007; 21(5): 662-8.

[PMID: 17447981]

[5] Rieder E, Tausk F. Psoriasis, a model of dermatologic psychosomatic disease: psychiatric implications and treatments. Int J Dermatol 2012; 51(1): 12-26.

[http://dx.doi.org/10.1111/j.1365-4632.2011.05071.x] [PMID: 22182372]

[6] Dalgard FJ, Gieler U, Tomas-Aragones L, et al. The psychological burden of skin diseases: a crosssectional multicenter study among dermatological out-patients in 13 European countries. J Invest Dermatol 2015; 135(4): 984-91.

[http://dx.doi.org/10.1038/jid.2014.530] [PMID: 25521458] 
[7] Fortune DG, Richards HL, Griffiths CE. Psychologic factors in psoriasis: consequences, mechanisms, and interventions. Dermatol Clin 2005; 23(4): 681-94.

[http://dx.doi.org/10.1016/j.det.2005.05.022] [PMID: 16112445]

[8] Fortune DG, Richards HL, Kirby B, et al. Psychological distress impairs clearance of psoriasis in patients treated with photochemotherapy. Arch Dermatol 2003; 139(6): 752-6.

[http://dx.doi.org/10.1001/archderm.139.6.752] [PMID: 12810506]

[9] Yosipovitch G, Greaves MW, McGlone F, Eds. Itch. New York: Marcel Dekker 2003.

[10] Ginsburg IH, Link BG. Feelings of stigmatization in patients with psoriasis. J Am Acad Dermatol 1989; 20(1): 53-63.

[http://dx.doi.org/10.1016/S0190-9622(89)70007-4] [PMID: 2913081]

[11] Schmid-Ott G, Künsebeck HW, Jäger B, et al. Significance of the stigmatization experience of psoriasis patients: a 1-year follow-up of the illness and its psychosocial consequences in men and women. Acta Derm Venereol 2005; 85(1): 27-32.

[http://dx.doi.org/10.1080/000155550410021583] [PMID: 15848987]

[12] Ginsburg IH, Link BG. Psychosocial consequences of rejection and stigma feelings in psoriasis patients. Int J Dermatol 1993; 32(8): 587-91.

[http://dx.doi.org/10.1111/j.1365-4362.1993.tb05031.x] [PMID: 8407075]

[13] Lu Y, Duller P, Van Der Valk PG, et al. Helplessness as predictor of perceived stigmatization in patients with psoriasis and atopic dermatitis. Dermatol Psychosom 2003; 4(3): 146-50.

[http://dx.doi.org/10.1159/000073991]

[14] Richards HL, Fortune DG, Griffiths CE, Main CJ. The contribution of perceptions of stigmatisation to disability in patients with psoriasis. J Psychosom Res 2001; 50(1): 11-5. [http://dx.doi.org/10.1016/S0022-3999(00)00210-5] [PMID: 11259795]

[15] Vardy D, Besser A, Amir M, Gesthalter B, Biton A, Buskila D. Experiences of stigmatization play a role in mediating the impact of disease severity on quality of life in psoriasis patients. Br J Dermatol 2002; 147(4): 736-42. [http://dx.doi.org/10.1046/j.1365-2133.2002.04899.x] [PMID: 12366421]

[16] Sampogna F, Picardi A, Melchi CF, Pasquini P, Abeni D. The impact of skin diseases on patients: comparing dermatologists' opinions with research data collected on their patients. Br J Dermatol 2003; 148(5): 989-95.

[http://dx.doi.org/10.1046/j.1365-2133.2003.05306.x] [PMID: 12786831]

[17] Beattie PE, Lewis-Jones MS. A comparative study of impairment of quality of life in children with skin disease and children with other chronic childhood diseases. Br J Dermatol 2006; 155(1): 145-51. [http://dx.doi.org/10.1111/j.1365-2133.2006.07185.x] [PMID: 16792766]

[18] de Jager ME, De Jong EM, Evers AW, Van De Kerkhof PC, Seyger MM. The burden of childhood psoriasis. Pediatr Dermatol 2011; 28(6): 736-7.

[http://dx.doi.org/10.1111/j.1525-1470.2011.01489.x] [PMID: 21692835]

[19] Warschburger P, Buchholz HT, Petermann F. Psychological adjustment in parents of young children with atopic dermatitis: which factors predict parental quality of life? Br J Dermatol 2004; 150(2): 30411. 
[http://dx.doi.org/10.1111/j.1365-2133.2004.05743.x] [PMID: 14996102]

[20] Koblenzer CS, Gupta R. Neurotic excoriations and dermatitis artefacta. Semin Cutan Med Surg 2013; 32(2): 95-100.

[http://dx.doi.org/10.12788/j.sder.0008] [PMID: 24049967]

[21] Gieler U, Consoli SG, Tomás-Aragones L, et al. Self-inflicted lesions in dermatology: terminology and classification--a position paper from the European Society for Dermatology and Psychiatry (ESDaP). Acta Derm Venereol 2013; 93(1): 4-12. [PMID: 23303467]

[22] Koo JY, Lee CS, Eds. Psychocutaneous Medicine. New York: Marcel Dekker 2003.

[23] Picardi A, Abeni D. Stressful life events and skin diseases: disentangling evidence from myth. Psychother Psychosom 2001; 70(3): 118-36. [http://dx.doi.org/10.1159/000056237] [PMID: 11340413]

[24] Evers AW, Verhoeven EW, Kraaimaat FW, et al. How stress gets under the skin: cortisol and stress reactivity in psoriasis. Br J Dermatol 2010; 163(5): 986-91. [http://dx.doi.org/10.1111/j.1365-2133.2010.09984.x] [PMID: 20716227]

[25] Verhoeven EW, Kraaimaat FW, Jong EM, Schalkwijk J, van de Kerkhof PC, Evers AW. Effect of daily stressors on psoriasis: a prospective study. J Invest Dermatol 2009; 129(8): 2075-7. [http://dx.doi.org/10.1038/jid.2008.460] [PMID: 19194471]

[26] King RM, Wilson GV. Use of a diary technique to investigate psychosomatic relations in atopic dermatitis. J Psychosom Res 1991; 35(6): 697-706. [http://dx.doi.org/10.1016/0022-3999(91)90120-D] [PMID: 1791583]

[27] Christian LM, Graham JE, Padgett DA, et al. Stress and Wound Healing Neuroimmunomodulat 2006; 13(5-6): 337-46.

[28] Scharloo M, Kaptein AA, Weinman J, Bergman W, Vermeer BJ, Rooijmans HG. Patients' illness perceptions and coping as predictors of functional status in psoriasis: a 1-year follow-up. $\mathrm{Br} \mathrm{J}$ Dermatol 2000; 142(5): 899-907. [http://dx.doi.org/10.1046/j.1365-2133.2000.03469.x] [PMID: 10809846]

[29] Renzi C, Picardi A, Abeni D, et al. Association of dissatisfaction with care and psychiatric morbidity with poor treatment compliance. Arch Dermatol 2002; 138(3): 337-42.

[http://dx.doi.org/10.1001/archderm.138.3.337] [PMID: 11902984]

[30] Serup J, Lindblad AK, Maroti M, et al. To follow or not to follow dermatological treatment--a review of the literature. Acta Derm Venereol 2006; 86(3): 193-7. [http://dx.doi.org/10.2340/00015555-0073] [PMID: 16710573]

[31] Heinen MM, van Achterberg T, op Reimer WS, van de Kerkhof PC, de Laat E. Venous leg ulcer patients: a review of the literature on lifestyle and pain-related interventions. J Clin Nurs 2004; 13(3): 355-66.

[http://dx.doi.org/10.1046/j.1365-2702.2003.00887.x] [PMID: 15009338]

[32] Evers AW, Duller P, de Jong EM, et al. Effectiveness of a multidisciplinary itch-coping training programme in adults with atopic dermatitis. Acta Derm Venereol 2009; 89(1): 57-63. [http://dx.doi.org/10.2340/00015555-0556] [PMID: 19197543] 
[33] Lewis V, Finlay AY. 10 years experience of the dermatology life quality index (DLQI). J Investig Dermatol Symp Proc 2004; 9(2): 169-80. [http://dx.doi.org/10.1111/j.1087-0024.2004.09113.x] [PMID: 15083785]

[34] Chren M-M, Lasek RJ, Quinn LM, Mostow EN, Zyzanski SJ. Skindex, a quality-of-life measure for patients with skin disease: reliability, validity, and responsiveness. J Invest Dermatol 1996; 107(5): 707-13.

[http://dx.doi.org/10.1111/1523-1747.ep12365600] [PMID: 8875954]

[35] Evers AW, Duller P, van de Kerkhof PC, et al. The impact of chronic skin disease on daily life (ISDL): A generic and dermatology specific health instrument. Br J Dermatol 2008; 158(1): 101-8. [PMID: 17999699]

[36] Lewis-Jones MS, Finlay AY. The Children's Dermatology Life Quality Index (CDLQI): initial validation and practical use. Br J Dermatol 1995; 132(6): 942-9. [http://dx.doi.org/10.1111/j.1365-2133.1995.tb16953.x] [PMID: 7662573]

[37] Ware JE Jr, Sherbourne CD. The MOS 36-item short-form health survey (SF-36). I. Conceptual framework and item selection. Med Care 1992; 30(6): 473-83. [http://dx.doi.org/10.1097/00005650-199206000-00002] [PMID: 1593914]

[38] Ehlers A, Stangier U, Dohn D, et al. Kognitive faktoren beim juckreiz: Entwicklung und zalidierung eines fragebogens. Verhaltenstherapie 1993; 3(2): 112-9.

[http://dx.doi.org/10.1159/000258752]

[39] Huizinga J, van Os-Medendorp H, Ros WJ, Grypdonck M, Lablans JA, Dijkstra GJ. Validation of the Dutch version of the itching cognitions questionnaire. J Nurs Meas 2012; 20(1): 35-46.

[http://dx.doi.org/10.1891/1061-3749.20.1.35] [PMID: 22679708]

[40] van Os-Medendorp H, Eland-de Kok PC, Ros WJ, Bruijnzeel-Koomen CA, Grypdonck M. The nursing programme 'Coping with itch': a promising intervention for patients with chronic pruritic skin diseases. J Clin Nurs 2007; 16(7): 1238-46.

[http://dx.doi.org/10.1111/j.1365-2702.2007.01590.x] [PMID: 17584341]

[41] Stangier U, Ehlers A, Gieler U. Measuring adjustment to chronic skin disorders: validation of a selfreport measure. Psychol Assess 2003; 15(4): 532-49.

[http://dx.doi.org/10.1037/1040-3590.15.4.532] [PMID: 14692848]

[42] Lawrence JW, Fauerbach JA, Heinberg LJ, Doctor M, Thombs BD. The reliability and validity of the Perceived Stigmatization Questionnaire (PSQ) and the Social Comfort Questionnaire (SCQ) among an adult burn survivor sample. Psychol Assess 2006; 18(1): 106-11.

[http://dx.doi.org/10.1037/1040-3590.18.1.106] [PMID: 16594819]

[43] Schmid-Ott G, Jaeger B, Kuensebeck HW, Ott R, Lamprecht F. Dimensions of stigmatization in patients with psoriasis in a "Questionnaire on Experience with Skin Complaints'. Dermatology (Basel) 1996; 193(4): 304-10.

[http://dx.doi.org/10.1159/000246275] [PMID: 8993954]

[44] Kupfer J, Keins P, Brosig B, et al. Development of questionnaires on coping with disease and itching cognitions for children and adolescents with atopic eczema. Dermatol Psychosom 2003; 4(2): 79-85. [http://dx.doi.org/10.1159/000072196] 
[45] Chida Y, Steptoe A, Hirakawa N, Sudo N, Kubo C. The effects of psychological intervention on atopic dermatitis. A systematic review and meta-analysis. Int Arch Allergy Immunol 2007; 144(1): 1-9. [http://dx.doi.org/10.1159/000101940] [PMID: 17449959]

[46] Lavda AC, Webb TL, Thompson AR. A meta-analysis of the effectiveness of psychological interventions for adults with skin conditions. Br J Dermatol 2012; 167(5): 970-9.

[http://dx.doi.org/10.1111/j.1365-2133.2012.11183.x] [PMID: 22924999]

[47] de Bes J, Legierse CM, Prinsen CA, de Korte J. Patient education in chronic skin diseases: a systematic review. Acta Derm Venereol 2011; 91(1): 12-7. [http://dx.doi.org/10.2340/00015555-1022] [PMID: 21264451]

[48] Staab D, Diepgen TL, Fartasch M, et al. Age related, structured educational programmes for the management of atopic dermatitis in children and adolescents: multicentre, randomised controlled trial. BMJ 2006; 332(7547): 933-8.

[http://dx.doi.org/10.1136/bmj.332.7547.933] [PMID: 16627509]

[49] Schut C, Weik U, Tews N, Gieler U, Deinzer R, Kupfer J. Psychophysiological effects of stress management in patients with atopic dermatitis: a randomized controlled trial. Acta Derm Venereol 2013; 93(1): 57-61. [PMID: 22983681]

[50] Fordham B, Griffiths CE, Bundy C. Can stress reduction interventions improve psoriasis? A review. Psychol Health Med 2013; 18(5): 501-14. [http://dx.doi.org/10.1080/13548506.2012.736625] [PMID: 23116223]

[51] Ehlers A, Stangier U, Gieler U. Treatment of atopic dermatitis: a comparison of psychological and dermatological approaches to relapse prevention. J Consult Clin Psychol 1995; 63(4): 624-35. [http://dx.doi.org/10.1037/0022-006X.63.4.624] [PMID: 7673540]

[52] Kabat-Zinn J, Wheeler E, Light T, et al. Influence of a mindfulness meditation-based stress reduction intervention on rates of skin clearing in patients with moderate to severe psoriasis undergoing phototherapy (UVB) and photochemotherapy (PUVA). Psychosom Med 1998; 60(5): 625-32. [http://dx.doi.org/10.1097/00006842-199809000-00020] [PMID: 9773769]

[53] Fortune DG, Richards HL, Kirby B, Bowcock S, Main CJ, Griffiths CE. A cognitive-behavioural symptom management programme as an adjunct in psoriasis therapy. Br J Dermatol 2002; 146(3): 458-65.

[http://dx.doi.org/10.1046/j.1365-2133.2002.04622.x] [PMID: 11952546]

[54] van Cranenburgh OD, Smets EM, de Rie MA, Sprangers MA, de Korte J. A Web-based, educational, quality-of-life intervention for patients with a chronic skin disease: feasibility and acceptance in routine dermatological practice. Acta Derm Venereol 2015; 95(1): 51-6.

[http://dx.doi.org/10.2340/00015555-1872] [PMID: 24733369]

[55] Bundy C, Pinder B, Bucci S, Reeves D, Griffiths CE, Tarrier N. A novel, web-based, psychological intervention for people with psoriasis: the electronic Targeted Intervention for Psoriasis (eTIPs) study. Br J Dermatol 2013; 169(2): 329-36.

[http://dx.doi.org/10.1111/bjd.12350] [PMID: 23551271]

[56] van Beugen S, Ferwerda M, Hoeve D, et al. A meta-analytic review of internet-based cognitive 
behavioral therapy for patients with chronic somatic conditions. J Med Internet Res 2014; 16(3): e88. [http://dx.doi.org/10.2196/jmir.2777] [PMID: 24675372]

[57] Ersser SJ, Cowdell F, Latter S, et al. Psychological and educational interventions for atopic eczema in children. Cochrane Database Syst Rev 2014; 1: CD004054.

[PMID: 24399641]

[58] Scheewe S, Schmidt S, Petermann F, et al. Long-term efficacy of an inpatient rehabilitation with integrated patient education program for children and adolescents with psoriasis. Dermatol Psychosom 2001; 2(1): 16-21.

[http://dx.doi.org/10.1159/000049632]

[59] Oostveen AM, Spillekom-van Koulil S, Otero ME, Klompmaker W, Evers AW, Seyger MM. Development and design of a multidisciplinary training program for outpatient children and adolescents with psoriasis and their parents. J Dermatolog Treat 2013; 24(1): 60-3. [http://dx.doi.org/10.3109/09546634.2012.672707] [PMID: 22390570]

[60] Grillo M, Long R, Long D. Habit reversal training for the itch-scratch cycle associated with pruritic skin conditions. Dermatology nursing/Dermatology Nurses'. Association 2007; 19(3): 243-8.

[61] Tey HL, Wallengren J, Yosipovitch G. Psychosomatic factors in pruritus. Clin Dermatol 2013; 31(1): $31-40$.

[http://dx.doi.org/10.1016/j.clindermatol.2011.11.004] [PMID: 23245971]

[62] Melin L, Frederiksen T, Noren P, Swebilius BG. Behavioural treatment of scratching in patients with atopic dermatitis. Br J Dermatol 1986; 115(4): 467-74.

[http://dx.doi.org/10.1111/j.1365-2133.1986.tb06241.x] [PMID: 3778815]

[63] van Minnen A, Hoogduin KA, Keijsers GP, Hellenbrand I, Hendriks GJ. Treatment of trichotillomania with behavioral therapy or fluoxetine: a randomized, waiting-list controlled study. Arch Gen Psychiatry 2003; 60(5): 517-22.

[http://dx.doi.org/10.1001/archpsyc.60.5.517] [PMID: 12742873]

[64] Schuck K, Keijsers GP, Rinck M. The effects of brief cognitive-behaviour therapy for pathological skin picking: A randomized comparison to wait-list control. Behav Res Ther 2011; 49(1): 11-7. [http://dx.doi.org/10.1016/j.brat.2010.09.005] [PMID: 20934685]

[65] Teng EJ, Woods DW, Twohig MP. Habit reversal as a treatment for chronic skin picking: a pilot investigation. Behav Modif 2006; 30(4): 411-22.

[http://dx.doi.org/10.1177/0145445504265707] [PMID: 16723422]

[66] Prazeres AM, Nascimento AL, Fontenelle LF. Cognitive-behavioral therapy for body dysmorphic disorder: a review of its efficacy. Neuropsychiatr Dis Treat 2013; 9: 307-16.

[PMID: 23467711]

[67] Ipser JC, Sander C, Stein DJ. Pharmacotherapy and psychotherapy for body dysmorphic disorder. Cochrane Database Syst Rev 2009; 1(1): CD005332.

[PMID: 19160252]

[68] Luteijn MC, Boonstra HE, Castelen G, et al. Psychodermatologie in de Nederlandse dermatologische praktijk. Nederland Tijdschr Dermatol Venereol 2011; 21: 545-9. 